\title{
Relationship on the Relational Benefit Effect of Oil Products on Customer Satisfaction
}

\author{
Muxue Jing ${ }^{1, *}$ and Xilai Jin ${ }^{2}$ \\ ${ }^{1}$ School of Management, Wuhan University of Technology, Wuhan, China, 430074 \\ ${ }^{2}$ School of Engineering, University of Florida, Gainesville, FL, US \\ Corresponding author: jmuxue@126.com
}

\begin{abstract}
In order to find out the relationship of relational benefit effect of oil products on customer satisfaction, the local fractional algorithm is proposed in this paper for data analysis. It is investigated the adjustment effect of alternative brand competitiveness and customer characteristics to this mechanism. The results show that the proposed algorithm can thus improve overall system performance substantially.
\end{abstract}

\section{Introduction}

With the acceleration of economic globalization pace, the environment that enterprises confront has changed enormously, that enterprises participate in the fierce international competition only by its own resources had been far from enough, It is necessary to achieve the goal of responding to the market fast with the help of the resources of other enterprises. So, supplier, manufacturer, retailer etc, must break the traditional boundary line to change from the traditional buying and selling relation into new-type partnership relation, However, some domestic enterprises have implemented supply chain management, and has made certain effect [1], but because of the lack of coordination and cooperation among enterprises and the lack the long-term plan and the whole optimization of supply chain, its application level and range still await to improve further. Rob's paper [2] regarding the optimization of the whole supply chain as the goal, beginning with the supply partnership relation interests, study the interest mechanism of the supply chain partnership relation. Its main content consists of the forming mechanisms, security mechanisms and allocation mechanisms of supply chain partnership relation interests [3].

The forming mechanism of supply chain partnership relation interests explain the reasons of the forming of the supply chain partnership relation interests to improve enterprise's the understanding to the supply chain partnership relation and its interests [3-4]; the security mechanisms of the supply chain partnership relation interests provide direct for enterprises to establish supply chain partnership relation, to keep and improve the operation efficiency of the whole supply chain; the allocation mechanism of the supply chain partnership relation have decisive actions on the foundation and successful operation of supply chain partnership relation, because it is all to obtain some economic benefits for any enterprise participating in supply chain partnership relation, if the synergy interests emerged in supply chain partnership relation cannot be allocated fairly and reasonably among the partners, supply chain partnership relation can't be for a long time, and its interests are not known where to begin either. The study of supply chain partnership relation interest mechanism can offer some guide for the domestic enterprises to establish successful supply chain partnership relation to participate in the international competition [5].

\section{Basic Framework}

To replace the transaction-oriented marketing as relationship-oriented is the most representative of marketing theoretical breakthrough and marketing practices during the past two decades. Different from traditional transaction marketing, relationship marketing focuses on the long-term interests of enterprises, by maintaining and strengthening the long-term relationships with customers to achieve enterprises' marketing objectives. Brand relationship is an important manifestation of the customer relationship, and seeking relationship stability and durability is the point of brand relationship management. With language expression of brand relationship management, brand relationship management should focus on the management of whole life cycle of brand relationship, because the long-term relationship-oriented marketing concept plays a key role for enterprises to achieve a competitive advantage status. From the perspective of the complete life cycle of brand relationship, brand relationship management should include the 
brand relationship to establish, maintain and renew. The management objects of the three stages are new customers, old customers, and relationship fracture customers [6-7].

At present, both from the enterprise management practice and from the academic research level, brand management focus on relationship establishment and maintain, the attention to the relationship fracture customers is far less than the first two stages. In fact, with the increased competition of customer resources and customer development and maintenance cost of ascension, to re-develop the relationship of fracture customers should be the new focus on brand relationship management. Under the condition of buyer's market, due to the selective enhancement of consumers, customer resources become more competitive. The tentacles of enterprise brand relationship management have to extend to relationship revival of fracture customers. The premise of effective brand relationship revival strategy is correctly grasp of what factors drive the customer-brand relationship revival behavior and how these factors work. However, the academic study on brand relationship revival has just begun. Driving factors of the brand relationship revival, especially the thinking of mechanism of action is still very insufficient. The biggest problem of the only scattered results is the lack of a clear theoretical basis and analysis framework of the system.

Aiming at the shortcomings of the theory research of the brand relationship revival and confusion of management practice, it is puts forward three issues to be addressed. Firstly, what factors drive customers to renew the fracture brand relationship? Secondly, how these factors act on the customer's intention to renew the brand relationship? Thirdly, which factors could influence the driving effects that the brand relationship revival had on relationship revival intention? Around the three questions, it is proposed the concept of customer perceived relationship revival value, and use critical incident technology, focus interview and other qualitative research methods developed the constituent elements of perceived relationship revival value. Guided by the theory of value-driven behavior of social exchange, based on the theory of rational behavior and technology acceptance theory, it is developed theoretical framework of perceived relationship revival value-emotion of relationship revival-brand relationship revival intention. And using 856 questionnaires customer data restaurants empirical test reveals the mechanism of customer perceived relationship revival value works on customer relationship revival intention by acting on customer perceived emotional of relationship revival, instead of brand competitiveness and customer characteristics and investigates. It is also investigated the adjustment effect of alternative brand competitiveness and customer characteristics to this mechanism.

\section{Algorithm}

The customer behavior intention of brand relationship revival has characteristics of situation dependencies and peculiarity dependencies. Consumer decision process is a process of complicated mentality. On the one hand, for the same customer, even though he tends to rebuild the relationship because of recovery value and relationship benefit, competing brands could impact the customer's decision. The more competitive the alternative brands are, the less possible the customer is to rebuild the relationship. On the other hand, Customer purchase behavior affected by its own characteristics. It is shows that the level of confidence and demand for diversity, involvement and other customers individual traits play a regulating effect on the relationship between customer relationship revival emotion and behavioral intentions in relation adjourned, which means that positive emotions may not be able to produce revival intention. The relationship revived is a prepaid trust to the service failure companies. In other words, it is an uncertain decision. Generally speaking, the customers with lower confidence have higher level of perceived risk than the general level, and they are likely to avoid the risk when faced with risk decisions. The customers with high level of demand diversity tend to make the decision by comparing the different brands, and they have low degree of stickiness, once there are ideal alternative brand, they are not willing to rebuild the relationship. Similarly, customers with high purchase involvement have features that they may shop around, make the decisions discreetly, assess brand fully, then it will not contribute to the management of relationship revival. The equation of basic function is as equation (1) as follows:

$$
\partial_{j}\left(C_{i j k l} \partial_{k} u_{l}+e_{k i j} \partial_{k} \varphi\right)-\rho \ddot{u}_{i}=0
$$

Under the linear relationship, basic equation is shown in equation (2):

$$
\partial_{j}\left(e_{i j k l} \partial_{k} u_{l}-\eta_{k i j} \partial_{k} \varphi\right)=0
$$

The linear differential equation can be expressed into the following simplified forms:

$$
\begin{aligned}
& L(\nabla, \omega) f(x, \omega)=0, \\
& L(\nabla, \omega)=T(\nabla)+\omega^{2} \rho J
\end{aligned}
$$

In which,

$$
\begin{array}{r}
T(\nabla)=\left\|\begin{array}{ll}
T_{i k}(\nabla) & t_{i}(\nabla) \\
t_{k}^{T}(\nabla) & -\tau(\nabla)
\end{array}\right\|, \quad J=\left\|\begin{array}{cc}
\delta_{i k} & 0 \\
0 & 0
\end{array}\right\|, \\
f(x, \omega)=\left\|\begin{array}{l}
u_{k}(x, \omega) \\
\varphi(x, \omega)
\end{array}\right\| \\
T_{i k}(\nabla)=\partial_{j} C_{i j k l} \partial_{l}, \quad t_{i}(\nabla)=\partial_{j} e_{i j k} \partial_{k}, \quad \tau(\nabla)=\partial_{i} \eta_{i k} \partial_{k}
\end{array}
$$


Consider an infinite situation, we have the equation (5) in the following:

\section{The Experiment and Analysis}

$$
L^{0}=\left\|\begin{array}{cc}
C_{i j k l}^{0} & e_{k i j}^{0} \\
e_{i k l}^{0 T} & -\eta_{i k}^{0}
\end{array}\right\|
$$

The theoretical framework can lay a foundation for the related research on brand relationship revival, and provide guidance for service enterprises brand relationship management practice.

Table 1 shows the common model-fit indices, recommended values and results of the test of structural model fitness. As shown in Table 1, comparison of all fit indices with their corresponding recommended values, the evidence of a good model fit was revealed. Fig. 1 presents the structural model results for the model.

The relationship benefit is focusing on the customer psychology and behavior characteristics in the latter part of brand life cycle enrich the theory research results of brand relationship from a dynamic perspective. How to revive the relationship, win back lost customers, extended the length of every customer relationship life cycle, to enhance the contribution of the customer relationship full-life cycle to service provider, is a new focal point in brand management and customer relationship management to service company. In-depth analysis of customer value demands and psychological-behavioral mechanisms in this stage, not only is beneficial to profound grasp of the brand relationship full-life cycle, but also enriched research results of the brand relationship from a dynamic perspective.

Table 1. The result of measurement model.

\begin{tabular}{|c|c|c|}
\hline Fit indices & Recommended value & Result \\
\hline $\mathrm{X}^{2} / \mathrm{df}$ & $<3.00$ & 2.73 \\
\hline GFI & $>0.90$ & 0.94 \\
\hline RMSEA & $<0.08$ & 0.05 \\
\hline
\end{tabular}

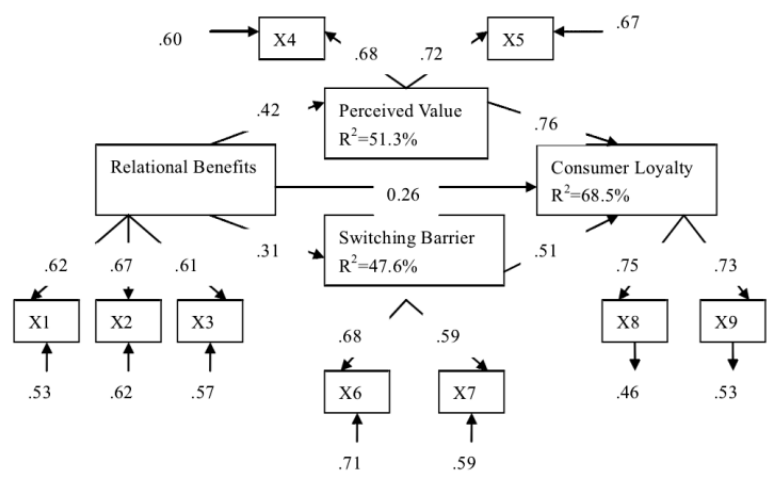

Fig. 1. Results of structure equation model.

\section{References}

1. Babak A, Kristian K, Martin M et al. Exploiting symmetries for scaling loopy belief propagation and relational training. Machine learning, 92(2013):91-132.

2. Babak A, Kristian K, Sriraam N et al., Lifted Online Training of Relational Models with Stochastic Gradient Methods. Machine learning and knowledge discovery in databases, 5(2012):585-600.

3. Chingarande A, Mzumara M, Karambakuwa RT. Does MERSOSUR possess comparative advantage? Journal of Economics, 5(2014): 341-349.

4. Eric T. G. W, Jeffrey C. F. T, Varun G et al., Examining the Relational Benefits of Improved interfirm information processing capability in Buyer-Supplier Dyads. MIS quarterly, 37(2013):149-173.

5. Gilles B, Cédric F, Benjamin G et al. Probabilistic Relational Verification for Cryptographic Implementations. ACM SIGPLAN Notices: A Monthly Publication of the Special Interest Group on Programming Languages, 49(2014): 193-205. 
6. Haixia G, Dawei L. Relationship of trustworthiness and relational benefit in electronic catalog markets. Electronic markets: The international journal on networked business, 24(2014): 67-75.Benrun Huang, Li Xia, Zhengguo Wu, Weiping Zhou. Control Strategy of A Dynamic Voltage Restorer (DVR) Based on Line Voltage Compensation. Energy Procedia, (2011), pp. 13-26.

7. Wei Dai, Mostafa Bassiouni. An improved task assignment scheme for Hadoop running in the clouds. Journal of Cloud Computing, (2013), pp. 21-33. 